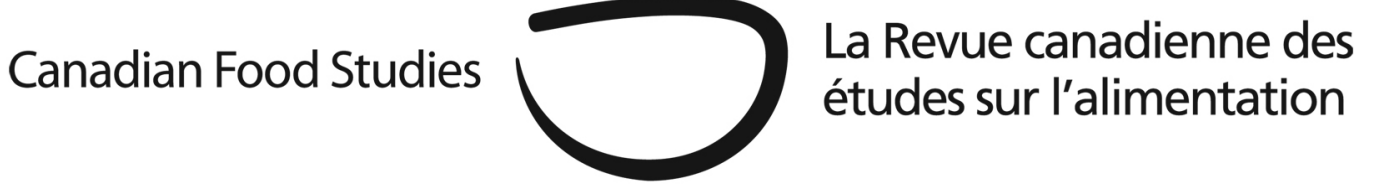

Original Research Article

\title{
Spaces for farmers in the city: A case study comparison of direct selling alternative food networks in Toronto, Canada and Belo Horizonte, Brazil
}

\section{Erin Pratley ${ }^{1}$ and Belinda Dodson ${ }^{2}$}

'Department of Geography, Western University, London, Ontario (corresponding author: epratley@gmail.com)

${ }^{2}$ Associate Professor, Department of Geography, Western University, London, Ontario

\begin{abstract}
The current focus of the Alternative Food Network (AFN) literature in the global North overlooks the reality of Southern AFNs and the potential contributions from studying Southern case studies. In this research, we used interviews and observation to determine how the differing valuations of 'local' food and farmers in two case study locations, one in the global North (Toronto, Canada) and one in the global South (Belo Horizonte, Brazil), affected the physical, economic, and political spaces in the city for farmers participating in the AFNs. The geographical concepts of scale, space, and place are central to understanding these networks. Drawing on work by Cook and Crang (1996) on 'geographical knowledges', we examined how farmers and customers reinforced and constructed different narratives of 'local' food, which was valued by affluent customers in Toronto but not by affluent customers in Belo Horizonte. In Toronto, farmers operated in physical spaces that put them in contact with affluent customers, and they were able to take advantage of pricing premiums at market and off-market economic spaces like specialty grocery stores and restaurants. In Belo Horizonte, farmers were relegated to marginal physical spaces, and had limited economic and political power. There were broader social justice implications related to whether the AFN operated mainly within affluent or marginal spaces. In agreement with the geographic literature, these case studies demonstrate that the social construction of scale, space, and place lead to the privileging of some actors over others in the AFN and within the city.
\end{abstract}

Keywords: Alternative Food Network, space, place, local food, direct selling, Canada, Brazil 


\section{Introduction}

The desire to create more sustainable and just food systems has resulted in a broad array of alternative networks (particularly in the global North). The term Alternative Food Network (AFN) embraces different kinds of emerging networks of producers, consumers, and other actors (administrators, intermediaries, activists, proponents) that seek to organize relationships between producers and consumers in different ways than in the industrial food system (Renting et al., 2003). Among AFNs that focus on local food, a dichotomy of global versus local is common. Global is associated with the market economy, large scale, industrial processes that degrade the environment; while local is associated with the moral economy, small scale, natural processes that protect and regenerate (Hinrichs, 2003). Critiques of AFNs often center on social justice concerns.

Allen (2008) notes that rather than being a transformative change to the dominant food system, AFNs may provide a 'bleeder valve' where privileged people participate in alternatives, and as a result feel like they are doing their part, but are through their participation merely isolating themselves from the negative aspects of the dominant food system. She maintains that this may create a two-tiered system where privileged AFN participants are active within their local AFN, but politically complacent at a broader scale. Others assert that social interactions within AFNs have the potential to shape consumers' ways of knowing about food and the food system, and change their actions towards more sustainable ones (Kerton \& Sinclair, 2010).

Most of the literature on AFNs has been developed in the global North, even though there are important insights to be gained from looking at AFNs in the global South (Abrahams, 2007). Looking at local levels, the false dichotomy of North and South is often exposed. Similarities exist between Southern and Northern AFNs, as well as local particularities, but to our knowledge, this type of comparison has not been documented. This study provides a unique opportunity to observe how one Northern and one Southern AFN are similar and different. With the paucity of case studies in the South, this case study cannot be assumed to be reflective of a broader trend or pattern, but it does provide a contribution from one Southern location.

The focus of this paper is on examining space, place, and the scale of the local from the perspective of farmers who interact with the city in various ways by participating in direct marketing, urban AFNs. Specifically, the cross-cultural case study comparison of two AFNs, one in Toronto, Canada and one in Belo Horizonte, Brazil, provides insight into how different valuations of 'local' food and farmers shapes the spaces for farmers in the city. This can help build our understanding of the implications of social constructions of scale, space, and place in AFNs in practice.

There were some key differences between the AFNs in Belo Horizonte and Toronto, including the consumer base size, selling location, and administrators; but there were also similarities, including a similar number of farmers participating, the focus on local food, and the structure of farmers selling produce directly in a major urban centre.

\section{Case Study Background: Toronto and Belo Horizonte}

\section{Toronto, Canada}

Toronto is the most populous city in Canada with 2.79 million inhabitants, and 5.5 million in the Greater Toronto Area (GTA) (City of Toronto, 2013). The city boasts an ethnically diverse 
population, of which about half were born in a country other than Canada (Statistics Canada, 2006). Major food retailing trends in Toronto include the growth of 'local' food markets, increasing options for obtaining ethnic and culturally-appropriate food, and specialty foods such as organics and products for specific dietary restrictions (Friedmann, 2007). Eighty-five percent of all Southern Ontarians still buy their food primarily from supermarkets (Metcalf Foundation, 2008), which have responded to the above trends in various ways. For example, Wal-Mart has committed to stocking 30 percent Ontario produce (Ajayi et al., 2010). Parallel to the emergence of this new food economy, the GTA has seen a steady increase in food insecurity since 1995. During 2009, food bank use in Toronto rose by 14 percent from approximately 874,000 to 997,000 visits (Daily Bread Food Bank, 2010).

Toronto has an active group of organizations trying to address issues of food security, inequality and social justice. These include the Toronto Food Policy Council, The Stop Community Food Centre and FoodShare. The latter is a not-for-profit originally established in 1985 in order to co-ordinate and deliver emergency food services. In the late 1980s, FoodShare shifted its mandate to long-term systematic change (FoodShare website, no date). One of their initiatives is The Farmers’ Market Network (TFMN), from which the case study markets were chosen. This network was initiated in 2006 with partial funding from the Project for Public Spaces (PPS). It includes a group of market organizers, whose markets:

...operate independently, differing in size, style and requirements, but...share a focus on supporting sustainable agriculture and building strong communities. We work together to share information, farmer referrals, and best practices, to help new market organizers, to advocate for positive city policies, and to raise the profile of farmers' markets. (TFMN website, no date)

At the time of this study, the network involved six markets which are run weekly by community members or not-for-profit groups. Managers from four markets agreed to participate in this research. The Dufferin Grove Market is a year-round organic market in operation since late 2002. It is the most established of the markets in the network, and widely considered to be a model of a successful market. It is located in an area with a growing affluent population but with a mix of affluent, middle income, and lower income residents. Stonegate is a seasonal market (June to October) located in a church parking lot on the border of a prosperous neighbourhood and a low-income one. It has been running since 2005, with a stated goal to serve the needs of lower-income residents that live adjacent to the market. Withrow Park is a seasonal market (May to October) started in 2006 in a park of an affluent neighbourhood. The Stop’s Green Barn Farmers' Market (Wychwood Market) started in 2007 with support from The Stop Community Food Centre as a seasonal market in a temporary location of a church yard, in a neighbourhood that is relatively affluent, yet also has a sizable low-income population. Shortly after the field research was concluded, the market moved and changed considerably in size and make-up. The fieldwork reflects the market prior to this change in location. The farmers interviewed for the Toronto-based research were all landowners, and excepting one farmer who owned hundreds of hectares of land, their land size ranged from two to 40 hectares. 


\section{Belo Horizonte, Brazil}

Belo Horizonte is the largest city in and the capital of the state of Minas Gerais, with a population of approximately 2.4 million in the city proper, and nearly 4.4 million in the greater metropolitan area (Institute Brasileiro de Geografia e Estatistica [IBGE], 2011). The city is surrounded by agricultural land, and much of it is mountainous, difficult to farm, and farmed by small farmers. The population is highly segregated into high-income areas and low-income 'favelas' (slums), often adjacent to one another. In the affluent neighbourhoods, supermarket chains and international fast-food chains such as McDonalds and Pizza Hut are prevalent. Belo Horizonte is distinct from most other Brazilian cities due to the strong and persistent presence of small grocers. This has been attributed to the municipal government's 'Sacalão ABC' program where produce stores are set up and licenced by the government, and must have 21 fresh fruit and vegetables sold at a fixed price below market cost (Farina, 2002). Food insecurity is a major issue in Belo Horizonte. In the early 1990s, an estimated 20 percent of all children under three years in the city were malnourished, which became the catalyst for the development of municipal food security programs in 1993 (Secretaria Municipal de Abastecimento [SMAB], 1995). The Belo Horizonte AFN is working within the broader context of Brazil's national 'Fome Zero' (Zero Hunger Program, or ZHP) policy regime, introduced in 2002 by the federal government.

The comprehensive approach in Belo Horizonte has been lauded as a model for other urban food security programs in Brazil under the ZHP. Unlike the federal ZHP that was meant to increase food sovereignty and support smallholder farmers, the Belo Horizonte program is focused specifically on urban food security. A suite of programs aim to intervene in the market, ensuring that locally grown produce is sold at affordable prices for lower-income citizens (Mafra, 2004). The programs include a popular restaurant (where a healthy meal is affordably priced), a school nutrition program, community gardens and the Sacalão ABC. The Direto da Roça (Direct from the Farm or DR) program was included in the portfolio of the Department of Food Production and Commercialization Assistance (Gerência de Apoio à Produção e Comercialização de Alimentos, or GAPCO). The DR program involves single farmer stalls in various locations throughout the city of Belo Horizonte. Supporting farmers from areas outside of the municipal boundary is a desired benefit, but not the program priority.

Farmers work with GAPCO to identify selling locations and to work through the various city approvals (such as neighbourhood council and the municipal traffic and planning office). The locations vary from street corners in the city's business district to plazas in middle-to-lower income neighbourhoods. At the time of fieldwork in 2007, there were 18 small farmers involved in the program. Five were located adjacent to Sacalão ABC grocers, while the rest were spread around the city. Farmers had options: they could sell their own or another DR farmer's produce at a stall, they could sell by themselves or hire employees, and they could also sell at more than one location. The price of produce was controlled by SMAB through a set pricing chart, although at times of year when produce was less bountiful (notably in the wet season) farmers were allowed to set their own prices for certain products. The resources of farmers participating in this program varied. The largest two landowners both inherited over 20 hectares of farmland, while six farmers had insecure access (rented land or hired hand) to smaller plots of land under 2.5 hectares. Two farmers had participated in a land occupation and subsequently gained land tenure through an agrarian reform program. 


\section{Methods}

Within AFN scholarship, qualitative methodologies have commonly been employed to understand the construction and practices of AFNs (e.g. Feagan \& Henderson, 2009; Hinrichs, 2003; Jarosz, 2008, 2011; Kloppenburg et al., 2000; Lamine, 2005). Our research applied qualitative case comparisons to understand the experiences, processes, and outcomes for farmers in the case study AFNs. We used informal in-depth interviews with farmers, formal interviews with other relevant informants (including government officials, NGO employees, customers, and market organizers), and observations at market and on-farm.

Table 1 quantifies the sources and data collected using each of these methods. In both case studies, we attempted to get a complete sample of the produce farmers in each AFN. In total, 17 farmers were interviewed in the Belo Horizonte case study, and 14 in the Toronto case study. Some of these farmers were interviewed once, while those who agreed were interviewed two or more times. Methods were not standardized between case study locations because of the importance of developing rapport in each case study location. Of note, the Toronto interviews were conducted on-farm because of the busy nature of the market, while the Belo Horizonte interviews were conducted mainly at-market. Notably, the Toronto farmers were comfortable with a voice recorder and the interviews were conducted in English (the lead author's primary language), while the Belo Horizonte farmers preferred no voice recorder. In that case, handwritten notes were used to record the interviews, which were conducted in Portuguese (the lead author's secondary language). The second method was direct observation in both Toronto and Belo Horizonte, mostly at markets rather than farms; these observations were documented in a field diary during and after the visits.

Table 1: Method, type of and amount of data collected

\begin{tabular}{|l|c|c|c|c|}
\hline \multirow{2}{*}{ Method } & \multicolumn{2}{|c|}{ Data Collected } & \multicolumn{2}{c|}{$\begin{array}{c}\text { Amount of Data Collected } \\
\text { (number of pages) }\end{array}$} \\
\cline { 2 - 5 } & Canada & Brazil & Canada & Brazil \\
\hline Interviews with Farmers & 14 & 17 & 292 (typed) & 380 (handwritten ) \\
\hline Observations at Market & $\sim 28$ hours & $\sim 37$ hours & 47 (handwritten) & 68 (handwritten) \\
\hline $\begin{array}{l}\text { Key Informant } \\
\text { Interviews }\end{array}$ & 7 & 12 & 26 (transcript) & 46 (typed notes) \\
\hline
\end{tabular}

\section{Constructing local food narratives}

Although local place embeddedness is typically the defining characteristic of an AFN, the meaning of 'local' as a scale, and the related identification of places as the appropriate origin of food sold in AFNs, cannot be simply assumed or asserted. Geographers Ian Cook and Philip Crang (1996) provide a useful concept through which to explore such place-based constructions in their examination of 'geographical knowledges'. They note that "foods do not simply come from places, organically growing out of them, but also make places as symbolic constructs, being deployed in the constructions of various imaginative geographies” (p. 140). These knowledges are employed by farmers to promote certain commodities and by consumers to justify their 
consumption (Morris \& Kirwan, 2010). According to Cook and Crang (1996), three types of geographic knowledges around food are constructed for and by the consumer: the settings (the context in which they are used); the biographies (how they move about the food system); and the origins (where they come from). Direct marketing alternatives, connecting farmers to consumers, allow for a sense of 'authenticity' to be attached to the construction of place because of the trust that develops between the farmer and the consumer (Holloway \& Kneafsey, 2004), leading to the construction of an 'authentically local' product. Comparing the different constructions and representations of 'local food' in each study highlights how place and scale are not a passive platform at which activities occur. Rather, they are defined by and are outcomes of these activities, and also create and enable these activities (Marston et al. 2009).

The place-based 'local food' narrative in each location was both reinforced and constructed by how food was presented in the physical space of the market. In North America, there has been a resurging interest in local food (Feagan 2007, Mount 2012), with selfproclaimed 'locavores' seeking out sources of local food and wanting to connect with local growers. Toronto farmers commonly drew on narratives that put their food directly in contrast to 'conventional' food when presenting it to customers. One farmer explained his thought process behind his 'straight from the farm' produce.

I suppose I am kinda [sic] a straight off the farm, sorta [sic]. My style, people are accustomed to buying dirty things from me too. I mean I do wash some things, you know presentation is important, stuff looks, it looks good on the table ... I don't lay out fancy blankets and I have some baskets that I put things up just because it contains it on the table but when you have 30-40 things on the table, you can't have a lot of presentation, so basically it is just right off the field.

Using Cook and Crang's (1996) idea of imaginative geographies, by leaving things 'dirty' and without 'fancy blankets' he is purposely invoking an image of the origins of the food (localfrom his own farm), the biography (picked by him, picked fresh) and the setting (a 'real' market stand). In addition, he is drawing on the 'nostalgia' of entrenched traditional ideas of the farm, as Holloway and Kneafsey (2000) suggest.

In contrast, farmers in Belo Horizonte tried to evoke a different geographical imagining. In the context of growing supermarket competition in the city, frequented by middle- and upperincome consumers (Reardon et al. 2008), farmers made attempts to draw on similarities to supermarket fare, and surpass it with cleanliness and safety. They tried to profit from the value placed on the 'modern' and distance themselves from the devalued 'local' and 'traditional'. The modern supermarket narrative focuses on maintaining sanitary and sterile conditions rather than 'straight from the farm' narratives like in Toronto. The Brazilian farmers cleaned produce meticulously, sprayed with water frequently, and straightened their produce display throughout the day. Cleanliness, both on farm and at the stand, was a point of pride. One farmer said "I like to wash produce a lot; people come by and think my produce is better than every other Direto da Roça producer, but it is because I keep my stand clean and neat.” The most common word used to discuss their produce was its 'beauty'. To maintain beautiful produce, farmers trimmed off any leaves or roots that they believed took away from the appearance. Customers also chose produce based on it being 'beautiful'. Both farmers and customers equated beauty to quality of produce, 
and this produce was trimmed, clean, and well-displayed. The narrative of this geographical imagining is constructed by presenting its origin as 'sterilized'; its biography as a mixture of 'local, yet just as good as large farms'; and the setting for selling as 'just as clean and orderly as the supermarket'. In constructing a place-based narrative there was a tension between the farmer wanting the consumer to know the food was 'local' (from their farm) but also 'the same as supermarket' food (which may or may not be local).

\section{Spaces for farmers in the city}

These constructions and narratives of place and scale reflect deeper relations of power that govern the use and production of space for farmers in the city. Within AFN scholarship, space is given little consideration as a construct. Cox (1998) provides a useful conception of space where power can be exerted, using the idea of 'spaces of engagement' and 'spaces of dependence'. He defines spaces of dependence as "those more-or-less localized social relations upon which we depend for the realization of essential interests and for which there is no substitute elsewhere; they define place-specific conditions for our material well-being and our sense of significance”, and spaces of engagement as "the space[s] in which the politics of securing a space of dependence unfolds” (Cox, 1998: p. 2). The differing valuations of local food led to specific spaces in each city open to farmers. In each case study, the AFNs opened new urban spaces for farmers: physical spaces (for markets or stands); economic spaces (at market and outside of the market); and political spaces (through engagement with urban citizens and institutions). Where these spaces opened, to what extent, and with what effect, varied greatly between the two case study locations.

\section{Physical spaces for farmers}

The opening of physical urban spaces for farmers is not widely discussed in the AFN literature. Perhaps this is because the site of a market is assumed to be merely a physical space, not as a representation of power. It is clear in these case studies that the physical market location has a profound impact for farmers, and space availability is related to how much power farmers have within both the AFN and the city.

The farmers' markets in Toronto are generally located where there is access to a relatively affluent population, providing physical access for farmers to consumers who can support them. The popularity of local food in Toronto is evident by new market spaces in recent years. In 2004, a guide to Farmers' Markets listed 11 markets in Metro Toronto (Toronto Star, 2004). By 2009, 33 markets were listed in Toronto (TFMN website, 2013). Barriers to opening and maintaining market space have resulted from conflicts with the City of Toronto Parks, Forestry and Recreation Department (PFRD), as mentioned by two market managers who operate in city parks. The demand for the markets from affluent urban residents has meant that these barriers are not true impediments, as they have continued to operate. The affluent consumer base exercises power in the city, for example, by contacting local city councillors to resolve issues with PFRD. Thus the valuation of local food has enabled farmers to access physical and social spaces in the city where they can connect to a powerful consumer base.

In contrast, in Belo Horizonte the physical spaces for farmers are in marginal areas, and the DR stands have mostly been kept out or removed from wealthy neighbourhoods. The city has a relatively affluent inner city core along the south end, commonly called the 'Contorno' area. A 
government-based key informant said that in the early 2000s, the mayor's office directed GAPCO to limit the number of sellers in the Contorno area, resulting in a major shift in location for many producers in the program and a drop in the number of farmers involved. At the time of fieldwork in 2007, there were 18 small farmers involved in the program, as opposed to 36 farmers in 1999 (Rocha 2001). Many program farmers have sought permission to put stands in Contorno neighbourhoods that currently do not have any DR stands, but they have been denied. The farmers believe that the neighbourhood associations in these areas do not want them. As one farmer told me, "People think our stands are ugly and [for the] poor." The President of the Association of Farmers in Direto da Roça found this to be a significant issue:

In the central [Contorno] region, farmers who are not already here cannot enter. There have been cases where locations have been taken away. The possibility of getting your space taken away is greater than the possibility of getting a space added [in this region]... It is tremendously difficult to create new spaces for selling. What is the difference between our stand and a newspaper stand like the one over there [across the street]? Why can't they make spaces for us just like for all the newspaper stands? Yes, there is [prejudice]. In every corner there is a newspaper stand. What is the difference between the space it occupies and the space I occupy here?

Since the primary goal of the program is to provide access to fresh produce for the urban poor, the focus on areas outside the Contorno is somewhat understandable. Yet, the exclusion of small farmers from this area is indicative of attitudes towards them. One program administrator admitted that five to six farmers left the program as licenses were revoked in the Contorno area. He explained that the city had promised to 'clean-up' the streets, which meant removing many vendors, including DR farmers. His statement that "first world cities don't have street vendors" reflects the view that street vendors do not belong in a 'modern' Belo Horizonte, as they reinforce an 'old fashioned' sense of place. The director responsible for DR, as well his supervisor, the Secretary for Food Sustenance and Food Security, both said that barriers with locating DR stands in the city centre come from other departments within the city, such as Transit, the Planning Department, and the Regional Council, suggesting reluctance to take responsibility for the decision to keep farmers out of the Contorno.

The exclusion of physical spaces has meant that most of the DR farmers removed from the Contorno area left the program, since they could no longer make a living. A long time DR farmer estimated that about 10 new farmers start the program every year, but they usually leave within a few months to a year because they are forced to locate in poorer neighbourhoods. The entire program is thus weakened.

\section{Economic spaces for farmers}

In Toronto, the valuation of local food and the physical access to affluent customers at market led to higher pricing for certain products, as was revealed by observation and interviews. The heirloom tomato was the most commonly mentioned example of this, and some farmers articulated their discontent with it: 
I don't want to be charging four dollars a pound for [heirloom] tomatoes, as an example, this is too much money for you. I know they shouldn't be priced that anyways. So, there is an element of elitism there that I have always opposed.

We keep our prices, we're pretty good...It's a really good price, so we're not gouging people, never think of it as that, because I do know some people - some farmers, some vendors that — and you see the price boards and you're like "oh, what are you doing?"-I grow those [heirloom] tomatoes, I know you don't have to charge a million dollars!

The heirloom tomato was seen as more historically authentic, a part of the place-based construction of 'local'. Although there was no general consensus over pricing, the ability of farmers to set prices demonstrated a certain economic empowerment for farmers participating at the urban markets. Taking advantage of consumers' willingness to pay more at a market allowed these farmers to break free from the fixed prices normally received for wholesale or supermarkets. However, some farmers were worried about the effects on customers who could not afford higher-priced produce. At the Stonegate Market (located at the border of a higherincome and lower-income neighbourhood), the market manager was consciously trying to keep food prices more affordable. A farmer at this market shared that “I can’t overprice myself, I try to keep things very reasonable” or, he believed, he wouldn't sell anything.

Farmers in Toronto were not limited to the economic space of the market. They found many other outlets for their produce, including Community Shared Agriculture (CSAs), new farmers' markets, small specialty grocery stores, and restaurants. Still, most of the farmers credited the market as the 'jumping-off' point for these other connections. One farmer remarked that the market and the other economic spaces were complementary. For example, almost all farmers in the Toronto market also sold to high end and often organic specialty stores. In one extreme case, a farmer estimated that only five percent of his total sales originated from the farmer's market (Stonegate), but because of the much larger percentage of sales made to specialty stores and restaurants in Toronto, he could still justify selling at market.

The opening of economic spaces outside of market allows for innovative partnerships. For example, a farming couple had formed a partnership to offer their CSA box at a retail location, saying "we're basically going to be their mobile produce department" once a week since the farmers have a refrigerated truck and the store has limited freezer space. A second example was a farming couple with a background in the restaurant industry who were taking advantage of connections with chefs, as another space that had opened for farmers in restaurants. The key to this relationship was their shared background, as they 'speak the same language'. Their estimated 70 percent of total sales to restaurants in Toronto meant that "we certainly make more doing restaurant deliveries than at the farmers' markets, so we never really pushed ourselves at these farmers' markets so much." They took requests to grow special crops for chefs, and based some of their planting on what chefs wanted and on what was popular on the The Food Network on television. They based their ordering and delivery system for restaurants, and oriented their future business for this market.

In contrast to the multiple economic spaces that opened up for Toronto farmers, Belo Horizonte had limited spaces for farmers, especially in wealthy neighbourhoods. Consumers in 
the global South, including Belo Horizonte, are not as affluent as those in Toronto and other Northern AFNs (Abrahams, 2007). The DR program set prices for produce, and there was some discussion over increasing the cost of certain items. Yet, as one farmer said, "You can't increase prices, because then you won't sell as much, so you will come out making less.” Similarly, the strategy to increase the price of produce such as heirloom tomatoes in Toronto would not be effective in Belo Horizonte. Here, the narrative around local food is devalued, including any type of 'traditional' produce, such as collard greens. Farmers noted that in recent years, collard greens had not been selling as much, and that their stalls mainly attracted older customers. This is in agreement with studies on supermarket versus farmers' market consumers elsewhere in Brazil (e.g. Hoppe et al. 2013). Yet, produce that was considered more 'modern' did not equate to value capture in Belo Horizonte. People generally chose the least expensive option. For example, given the choice among three types of lettuce-an iceberg-type lettuce (at 50 cents), Boston lettuce (at 75 cents) and Romaine (at \$1.50)—most customers at one stand chose the least expensive option. According to the farmer, all of these were relatively similar in terms of inputs and labour, so the price difference was an attempt by him to capture some value, but he questioned if it was worth offering the Boston and Romaine lettuce varieties at all.

There was some limited economic empowerment in the DR program. The farmers effectively cut out the intermediary by selling directly, yielding a greater return. Farmers frequently stated that 'money in my pocket' (immediate payment) was a benefit of participation in the program. Nevertheless, they had little power to decide and set a fair price for their produce as the prices of inputs and on-farm factors changed. At certain times of year, farmers claimed that prices were fair. However, both weather and prices for inputs varied, and at times the fixed maximum price list rule was lifted by program administrators. During the 2007 field season in Belo Horizonte, there was a period of heavy rains that flooded many of the farmers' fields, and production suffered. Farmers were allowed to sell above the price list as a result, yet generally they chose not to. One farmer had to purchase his greens from another DR farmer during this period and was forced to sell at cost, since he was worried about losing customers if he did not have any produce or sold it at a higher price. Another farmer actually lowered her price during this same rainy period, despite the fact she had fewer greens to sell. She felt it was unfair to sell smaller, and in her words 'uglier', greens for the usual price. This demonstrates the linkages between the 'beauty' narrative prevalent in Belo Horizonte and the prices that farmers were able to capture. It may also speak to the differences with the Toronto consumer who may not mind buying 'uglier' greens to support the farmer during bad weather conditions, and the Belo Horizonte consumer who is looking only for the best economic value.

The one economic outlet outside of the market stall that Belo Horizonte farmers had some success with was restaurants. Unlike in Toronto, where restaurants purchased from local farmers because they were 'local', restaurants in Belo Horizonte purchased mostly for convenience and price. The space for farmers was again limited by the limited valuation of 'local' as a place construction. Five of the farmers sold to restaurants, and two of them estimated that this yielded 20 percent of their monthly sales. The rest, who sold minimally or not at all to restaurants, believed that the barrier was primarily their stall location, as most were located outside of the wealthy restaurant areas. Since local produce was not valued, chefs were not willing to go out of their way, nor pay a premium price, for DR farmers’ products.

Another economic space in Belo Horizonte from which farmers are notably absent was the suite of programs associated with SMAB. Five farmers were located adjacent to Sacalão ABC (private public partnership) grocers, who were licensed and somewhat price-regulated by 
the municipal government. In these cases, there were different informal agreements between the grocers and the farmers. For example, in one case, the Sacalão did not sell the same types of produce as the farmer, who limited his sales to agreed-upon produce. In another case, the grocer would buy produce from the farmer if the price was lower than other wholesalers. Other than these very limited arrangements, the DR farmers did not sell to other SMAB programs, such as the popular restaurant or the school programs. When asked about this, the Under-Secretariat agreed it was an issue; however, he noted that logistically it was easier to run the programs with lower costs if they sourced from larger wholesalers. He admitted that it would be ideal to support local small farmers like the DR ones, but that realistically SMAB is not set up to do so, since all of the departments and programs are run separately. The fact that even this economic space is closed, within the actual municipal department that is overseeing the DR program, demonstrates how few spaces have been opened for DR participants outside of the market stand.

\section{Political spaces for farmers}

Farmers in both case studies depended on income generated within the AFN to sustain their livelihoods; therefore the cities can be seen as 'spaces of dependence' (Cox, 1998) for them. In both Toronto and Belo Horizonte, farmers faced a situation where the majority of decisions about the AFN were made in the city, a space where they were political outsiders. City governments, responsible for setting policies and programs that affect the farmers, were primarily responsible to their own citizens. Therefore it was crucial that the farmers could depend on citizen support, especially those with connections and power in the city.

In Toronto, farmers were empowered by connections to affluent urban customers, who had influence in the city. The AFNs therefore open up 'spaces of engagement' for farmers (Cox, 1998). Weekly contact with this segment of society gave farmers the opportunity to share their concerns and experiences. The farmers in this study, when asked to describe their customers, used terms such as 'educated', and 'knowledgeable'. One farmer thought that, in Toronto, "most people are really aware. I think the average urban Toronto market consumer is pretty educated these days.” Knowledge was shared informally at the market as well. Another farmer stated, “It's great, it's like a big interaction that's all about sharing and food is meant to be shared, right. And knowledge is meant to be shared.” In addition to market space, farmers and market managers had access to affluent and educated consumers through the internet and email. Farmers' websites and market listservs, for example, informed consumers about what to expect at the market and what was happening on the farm, especially in times of extreme weather. The listservs also acted as a political space, to influence the affluent consumer. As one farmer explained:

And what she [the market manager] does too if she's ever worried about what's going on, she runs direct to the customers. She'll send a mailer [on the listserv] and then people get right back to her with support, so there's a good support system there. I try not to get too political. I know lots of people-I think at [this market] and the markets we go to, we've got plenty of people that know how to talk.

They are not citizens of Toronto, however, and thus farmers' political space is still limited; but they have a conduit through their consumers. In one example, political power was exercised 
when the city introduced new regulation wording in farmers' market permits in March 2008. The market managers feared this would lead to drastic changes in what farmers could take to market, or would make the markets ineligible for a permit. The managers were able to organize and gain support from their customers, so that no change was made to the Farmers' Market policy. Affluent customers are generally only in contact with a small contingent of farmers in an AFN, not all small farmers in the region, so their action reflects these interests.

Conversely, the farmers in Belo Horizonte lacked access to influential people within the city, and therefore lacked power within the city. Here, the city may be a space of dependence for farmers, but cannot broadly be interpreted as a space of engagement. The farmers had some support in the local government within the secretariat. However, as the Under-Secretariat of SMAB remarked, government's main priority was the citizens of Belo Horizonte, not farmers residing outside of the city. As discussed above, farmers removed from the Contorno area did not have the political power to stop this marginalization. This demonstrates how limited their influence is, and how decisions that affect them in the city are made without their representation or voice being heard.

In some rare cases farmers did have some power, such as the farmer whose community lobbied on her behalf in a low-to-middle-income area. A small grocery store located just down the street was actively trying to get rid of her market stand. The owner approached her as she was setting up her stand early in the morning, calling her names and threatening her, and finally lobbying the government to have her removed from the program. However, a group of her customers started a petition, and the local bakery and pharmacy also helped collect signatures for her to stay. The grocery store ended up leaving that location, and thanks to the engaged local community and their petition, her stand was not removed. This group was notably not elite, but they held influence within the boundaries of their low-to-middle-income neighbourhood.

Farmers in Belo Horizonte, because of their lack of political power, worry about the permanence of the both their individual stands and the broader program. Since it is a municipal program, and the municipal government is elected every four years, tension is particularly high around election time (although farmers cannot vote since they are not citizens in Belo Horizonte). One farmer worried that a change of political party in power might mean the end of the program. A new party may want to create their own legacy; DR is a part of the Partido dos Trabalhadores (PT) legacy. Even with the PT government in power, during their two terms in office, the program weakened. As one famer said, "It is not like we can do anything about it, politicians have the power." One farmer believed that, "If there were a hundred farmers in the program, it would be a lot harder to remove." He felt that the weakening of the program related back to the removal of farmers from the public eye in the Contorno, equating the 'public eye' to the middle- and upper-class population living in the city centre.

\section{Conclusions - space, place, and power in AFNs}

One of the most striking differences in the experiences of the farmers in Belo Horizonte and Toronto was revealed through different narratives around local food. These showed very different social classes of consumers who participated in each AFN, and how this was associated with very different physical, economic, and political spaces for farmers in the city. Farmers in Toronto draw on the valuation of the 'local' scale, while in Belo Horizonte, the devaluation of the 'local' led farmers to divorce their produce from place-based narratives of local, and to recreate the 'placeless' food of supermarkets. As geographer David Harvey (1996) noted, 'local' 
is a value-laden term, and an unreflexive localism (accepting the local without any thought as to how it is constituted) can lead to social exclusion of certain classes. He states: "the local' as a concept intrinsically implies the inclusion and exclusion of particular people, places and ways of life. The representation of the local and its constructs — quality, embeddedness, trust, careprivilege certain analytical categories and trajectories” (p. 461).

Clearly, AFNs must be profitable for participating farmers in order to attract and keep them in the city, and opening physical and economic spaces of privilege in Toronto does benefit farmers. Yet, there are broader social justice implications. The Toronto market spaces were targeted to more affluent customers, potentially excluding those with lower incomes. This agrees with other work in North America on farmer's markets (e.g. Alcon 2008, Slocum 2008). Work by Campigotto (2010) on the Wychwood Barns market found evidence of increased economic and race privilege after its re-location to the Green Barn market, creating an even more exclusionary space. Some market locations in Toronto may be acting as a 'bleeder valve' for the privileged few who inhibit the market space and are active on its behalf, limiting their political activity to a space of privilege (Allen, 2008). Other markets in Toronto, such as the aforementioned Stonegate farmers' market, showed configurations that potentially benefit farmers but may also be more socially just. This suggests that if the 'burden' of cost can be put on the high-end consumer through venues like specialty stores and restaurants, it can subsidize access to the AFN for the low-income consumer. In this scenario, the farmer can still earn the higher margins they need for more labour-intensive production, although less so than if combining specialty store sales with a more affluent market.

In Belo Horizonte, the lack of physical and economic space was problematic for farmers. The AFN aimed to improve access to lower income customers, and the government kept farmers physically distant from spaces of privilege. The devaluation of local food in Belo Horizonte, in contrast to the valuation of supermarket fare, meant less demand for DR stalls by the affluent population. Although keeping farmers in more marginal spaces and controlling prices may be just for the poor urban consumer, the result is closed economic and political spaces for farmers. If space in the Contorno were to be opened for farmers even for a limited time weekly, and if pricing were liberated there, the AFN could benefit from a model that would enhance spaces for local food in the city.

This study has provided an example of the multi-dimensional differences, for both consumers and small-scale farmers, between AFNs in the global South and North, as asserted by Abrahams (2007). The spaces for farmers in the city reflect the power of the class of customers with whom the farmers primarily interact. The spaces for farmers also reinforce urban class divisions by putting farmers 'in their place', whether it be in more affluent spaces in Toronto or in more marginalized spaces in Belo Horizonte.

A limitation of this study is that it the case studies cannot be generalized as representative of the AFN situation in the global North or South. However, the methodology of examining AFNs in terms of the physical, economic, and political spaces experienced by farmers and local residents can be replicated in other locations, thus broadening the evidence base on which to build further comparative analysis. Adopting a geographical perspective allows for a critical examination of how scale, space, and place are constructed and articulated in AFNs, in ways that are both reflective and constitutive of political and economic power. 


\section{References}

Abrahams, C. (2007). Globally useful conceptions of Alternative Food Networks in the Developing South: The Case of Johannesburg's Urban Food Supply System. in: D. Maye, L. Holloway and M. Kneafsey (Eds.) Alternative Food Geographies. Amsterdam: Elsevier Ltd.

Ajayi, J., Denson, C., Heath, B., \& Wilmot, K. (2010). 2010 Toronto Food Sector Update. Prepared for City of Toronto-Economic Development and Culture. Toronto, Canada.

Alcon, A.H. (2008). From value to values: sustainable consumption at farmers markets. Agriculture and Human Values 25:487-498.

Allen, P. (2008). Mining for justice in the food system: perceptions, practices and possibilities. Agriculture and Human Values 25:157-161.

Campigotto, R.M. (2010). Farmers Markets and their practices concerning income, privilege and race: A case study of Wychwood Artscape Barns in Toronto. Unpublished Masters Thesis. University of Toronto.

City of Toronto. (2013). Toronto’s Racial Diversity. Retrieved from: http://www.toronto.ca/toronto_facts/diversity.htm

Cook, I., \& Crang, P. (1996). The world on a plate: culinary culture, displacement and geographical knowledges. Journal of Material Culture 1, 131-153.

Cox, K. (1998). Spaces of dependence, spaces of engagement and the politics of scale, or: looking for local politics. Political Geography 17, 1-23

Daily Bread Food Bank. (2010). Daily Bread Food Bank Annual Report. Daily Bread Food Bank. Toronto, Canada.

Farina, E.M.M.Q. (2002). Consolidation, Multinationalisation, and Competition in Brazil: Impacts on Horticulture and Dairy Products Systems. Development Policy Review 20(4), 441-457.

Feagan, R., \& Henderson, A. (2009). Devon Acres CSA: Local Struggles in a Global Food System. Agriculture and Human Values 26(3), 203-217.

Foodshare website. (No date). FoodShare Mandate. Retrieved from: www.foodshare.ca

Friedmann, H. (2007). Scaling up: Bringing public institutions and food service corporations into the project for a local, sustainable food system in Ontario. Agriculture and Human Values 24, 389-398. 
Harvey, D. (1996). Justice, Nature and the Geography of Difference. Hoboken: WileyBlackwell.

Hinrichs, C. (2003). The practice and politics of food system localization. Journal of Rural Studies 19 (1), 33-45.

Holloway, L., \& Kneafsey, M. (2004). Producing-consuming food: closeness, connectedness and rurality. In: Holloway, L., Kneafsey, M. (Eds.), Geographies of Rural Cultures and Societies. London: Ashgate.

Institute Brasileiro de Geografia e Estatistica. (2011). IBGE Releases 2011 Population Estimates- English Edition, Brasilia.

Jarosz, L. (2008). The city in the country: Growing alternative food networks in Metropolitan areas. The Journal of Rural Studies 24, 231-244.

Jarosz, L. (2011). Nourishing Women: Toward a feminist political ecology of Community Supported Agriculture. Gender, Place and Culture 18, 3:307-326.

Kerton, S., \& Sinclair, J. (2010). Buying local organic food: a pathway to transformative learning. Agriculture and Human Values 27, 401-413.

Kloppenburg J., Lezberg, S., De Master, K., Stevenson, G.W., \& Hendrickson, J. (2000). Tasting food, tasting sustainability: Defining the attributes of an alternative food system with competent, ordinary people. Human Organization Summer, 1-13.

Lamine, C. (2005). Settling Shared Uncertainties: local partnerships between producers and consumers. Sociologia Ruralis 45(4), 324-345.

Mafra, L.A. (2004). O minicipio na gestao de politicas locais de seguranca alimentar: regulacao de Mercado e assistencia alimentar em Belo Horizonte. Unpublished MA. UFRRJ, Rio de Janeiro.

Marston, S.A., Jones III, J.P., \& Woodward, K. (2009). Scale. In R. Peet et al (Eds). The Dictionary of Human Geography, 5th Edition. Hoboken: Wiley-Blackwell.

Metcalf Foundation. (2008). Food Connects us all: Sustainable Local Food in Southern Ontario. Toronto: Metcalf Foundation.

Morris, C., \& Kirwan, J. (2010). Food commodities, geographical knowledges and the reconnection of production and consumption: The case of naturally embedded food products. Geoforum 41, 131-143.

Mount, P. (2012). Growing local food: scale and local food systems governance. Agriculture and Human Values 29, 107-121. 
Reardon, T., Timmer, C., \& Berdegue, J. (2008). The rapid rise of Supermarkets in Developing Countries: Induced Organizational, Institutional and Technological Change in Agri-food systems. In E.B. McCullough et al. (Eds) The Transformation of Agri-Food Systems: Globalization, Supply Chains and Smallholder Farmers. London: FOA and Earthscan.

Renting, H., Marsden, T., \& Banks, J. (2003). Understanding alternative food networks: exploring the role of short food supply chains in rural development. Environment and Planning A 35, 393-411.

Rocha, C. (2001). Urban Food Security Policy: The Case of Belo Horizonte, Brazil. The Journal for the Study of Food and Society 5(1), 36-47.

Slocum, R. (2008). Thinking race through corporeal feminist theory: divisions and intimacies at the Minneapolis Farmers’ Market. Social \& Cultural Geography 9(8), 849-869.

Secretaria Municipal de Abastecimento (SMAB). (1995). Politicas Publicas, Inovacao no Abastacemento Alimemtar em Belo Horizonte. Belo Horizonte: PBH.

Statistics Canada. (2006). Community Profile- Toronto, 2006 Census. Statistics Canada. Retrieved from: http://www12.statcan.ca/censusrecensement/2006/dppd/prof/92591/details/page.cfm?Lan $\mathrm{g}=\mathrm{E} \& \mathrm{Geo} 1=\mathrm{CD} \&$ Code1 $=3520 \& \mathrm{Geo} 2=\mathrm{PR} \&$ Code2=35\&Data=Count\&SearchText=Toro nto\&SearchType $=$ Begins $\&$ SearchPR $=01 \& B 1=$ All \&Custom $=$

TFMN website. (2013). Toronto Farmers’ Market Network. Retrieved from: www.tfmn.ca

The Toronto Star. (2004). Guide to Farmers' Markets. The Toronto Star. Retrieved from: http://dufferinpark.ca/market/pdf/thestarfarmersmarkets.PDF 